\title{
The Relationship Between Family-Friendly Workplace Policies and Accountant Turnover
}

\author{
Katie Landgraf \\ University of Hawaii - West Oahu
}

\begin{abstract}
Prolonged high turnover rates have caused a shortage of accountants; unfortunately, managers have not successfully taken action to avoid these circumstances. Reducing the high turnover is necessary for accountant managers to replenish the accountant shortage, reduce turnover costs, and protect the accounting industry's reputation for supporting its employees. Grounded in the social exchange theory, the purpose of this quantitative correlational study was to examine the relationship between three familyfriendly policies, childcare support, alternative work schedules, and work-family culture and accountant turnover intention. The participants comprised of 185 accountants who responded to the NSCW questionnaire. The results of the multiple regression analyses were significant, indicating that formal and informal family-friendly policies were significantly related to turnover intention. Further, demographic subgroups displayed different relationships between variables.
\end{abstract}

Keywords: family-friendly policies, accountants, turnover, work-family culture, alternative work schedules, childcare support

\section{INTRODUCTION}

The accounting industry lacks family-friendly policies to support the workforce (Socratous, Galloway, \& Kamenou-Aigbekaen, 2016). In 2019, an estimated 7.17 million jobs or about $4 \%$ of the U.S. workforce were in the accounting industry (U.S. Bureau of Labor Statistics, 2019). The rapid growth of 5\% in the accounting industry surpassed all other industries from 2018 - 2019 (U.S. Bureau of Labor Statistics, 2019). The lack of family-friendly policies not only affects the accounting industry but also a sizable portion of the current and future U.S. workforce.

Family-friendly policies help the workforce manage their diverse work and family needs. Such policies could incorporate formal or informal programs, which include flexible scheduling arrangements, flexible work location, childcare or elderly care services, parental leave, job sharing, and sick leave (Garg \& Agrawal, 2020). Researchers have emphasized the importance of examining the work-family culture when studying family-friendly policies to demonstrate the workforces' abilities to use established policies without repercussions (Shauman, Howell, Paterniti, Beckett, \& Villablanca, 2018; Vyas et al., 2017). Further research links the availability and use of formal and informal family-friendly policies to increased job satisfaction and decreased turnover intentions (Thakur \& Bhatnagar, 2017; Yu, 2019). Gim and Ramayah (2020) revealed the need for employers to support accountants through policies to reduce work-family conflict and turnover intentions. Employers that incorporate policies to balance work and family obligations could enhance the accounting industry. 
Accounting administrators who consider family-family policies could reduce turnover. In 2017, accountant turnover intentions led to a turnover rate of $17 \%$, which is significantly higher than the ideal turnover rate of $8 \%$ (George \& Wallio, 2017; Moon, 2017). The shortage of accountants created a crisis in 2017 for the public accounting industry (George \& Wallio, 2017). The accountant shortage illustrated the misalignment between the family-friendly policies in public accounting firms and employee perceptions. I addressed this need in my study by examining the relationship between family-friendly policies and employee turnover intention in the accounting industry.

\section{LITERATURE REVIEW}

\section{Social Exchange Theory}

Based on the context of social exchange theory, when managers support employees with benefits (e.g., family-friendly policies), employees feel compelled to stay with the organization (Bagger \& Li, 2014). Homans (1958) originally designed the social exchange theory to study individuals' actions from an exchange; however, Blau (1964) added an economic component that incorporates a reasonable fairness to the exchange. When managers exchange something of value, employees tend to be more committed (Engelbrecht \& Samuel, 2019).

\section{Social Exchange Theory in the Workplace}

When managers can supply employees with appropriate benefits, employees may seem more committed to the organization, hence reducing employee turnover intention. Researchers used the social exchange theory to demonstrate support for reducing employee turnover intention through the exchange of formal and informal organizational support (Chen, Zhang, Sanders, \& Xu, 2018; Rasheed, Iqbal, \& Mustafa, 2018; Yu, 2019). Low, Ong, and Tan (2017) found that managers should focus their attention on corporate social responsibility for all stakeholders, particularly employees. Managers can exhibit their support by allowing employees to balance their work and family needs. This balance allows for organizations to display support not just for their employees, but also their families.

Some researchers used the social exchange theory to study the effects of family-friendly policies on employee behaviors. For example, by utilizing the social exchange theory, Afonja (2019) found that employees are more "sustainable and committed" to an organization when managers offer family-friendly policies (p. 11). Yu (2019) further evaluated the use of six different family-friendly policies comprising flexible work schedules, flexible work location, health programs, worker support programs, child-care support programs, and elderly support programs. Findings outlined that the exchange of just one familyfriendly policy made a positive difference in employees' satisfaction and commitment to the organization (Yu, 2019). Researchers also used the social exchange theory to outline the relationship between employees and their managers, highlighting that when a good relationship exists, the employee has less work and family interferences (Tummers \& Bronkhorst, 2014). Essentially, when managers offer and support the use of family-friendly policies, employees are more likely to be pleased with their employment. Researchers were able to use the social exchange theory to highlight an exchange of employee commitment.

Some researchers used the social exchange theory to study the influences employers have on employee turnover intention. Rasheed et al. (2018) found that employees are more likely to intend to leave their job when work and family conflict is present. Afzal, Arshad, Saleem, and Farooq (2019) also utilized the social exchange theory to study the effects of manager support and employee turnover intention. The researchers found a significant inverse relationship between manager support and employee turnover intention, suggesting a need for managers to implement formal and informal policies to demonstrate employee-level support (Afzal et al., 2019). De la Torre-Ruiz, Vidal-Salazar, and Cordón-Pozo (2019) discovered that the social exchange theory is necessary to explain how employees willingly commit to an organization when managers actively meet the employees' needs. Managers are typically in control of employee' policies; therefore, employees expect managers to take that control very seriously.

Relating to this study even further, some researchers utilized the social exchange theory when studying a sample of accountants. Cannon and Herda (2016) studied the influence that organizational commitment 
has on accountants' turnover intention and found an inverse relationship. Researchers measured organizational commitment based on the level of fairness and support from the organization, which distinctly relates to offering policies that, like family-friendly policies, support employees (Bae \& Yang, 2017). Accountants expect support and rewards from their employers and are more willing to stay if the rewards align with their desires (Cohen, Dalton, Holder-Webb, \& McMillan, 2020). Al-Shbiel, Ahmad, AlShbail, Al-Mawali, and Al-Shbail (2018) also utilized the social exchange theory to discover that as accountants feel that they are being treated fairly at work (distributive justice), their intent to leave decreases. Relative to this study, the distributive justice survey included a question on the accountants' perception of fairness of their work schedule (Al-Shbiel et al., 2018). The review of such research identified the influence that manager support and company rewards have on accountants' intention to stay or leave the company.

\section{Family-Friendly Policies}

The studied components of family-friendly policies vary between researchers. Some researchers addressed formal policies such as paid sick leave, parental leave, flexible work schedules, childcare support, and flexible work location (Afonja, 2019; Su, Li, \& Curry, 2017; Wadsworth \& Facer, 2016). Researchers included these formal policies to demonstrate a more creative approach to supporting employees beyond a basic paid sick leave policy. Recent publications included informal policies such as a culture of family support, manager and colleague behaviors, and organizational justice (Feeney \& Stritch, 2019; Las Heras, Bosch, \& Raes, 2015; Low et al., 2017; Rasheed et al., 2018). Researchers found an opportunity to assess beyond what is formally established in an organization to understand if the culture supports a balance of family and work responsibilities. From the review of publications, a combination of formal and informal family-friendly policies seemed to encompass such policies' availability and acceptance.

In this study, I combined formal and informal policies to assess the level of support given to employees to balance their work and family obligations. Feeney and Stritch (2019) emphasized the importance of assessing formal and informal policies and incorporated variables such as childcare offerings, a flexible schedule, and a culture supporting family needs. Hwang (2019) combined formal and informal familyfriendly policies to evaluate childcare support, work schedules, and manager and coworker support. Although these researchers stressed the importance of a broad view of such policies' availability and use, Feeney, Stritch, and Hwang did not review the relationship of these policies to employee turnover intentions.

Ahmad, Shaw, Bown, Gardiner, and Omar (2016) further supported the need to incorporate formal and informal family-friendly policies by assessing flexible work schedules on job characteristics and employee turnover intentions. The components of job characteristics include "job demands, control, and support" shown to employees and facilitated by managers and coworkers (Geurts et al., 2005, p. 323). This support helps shape a family-friendly work environment and culture needed to accept the use of these policies. Furthermore, including employee turnover intentions highlights the implications of well-structured familyfriendly policies. As established by these researchers, I incorporated childcare support, alternative work schedules, and work-family culture as the independent variables and employee turnover intentions as the dependent variable.

\section{Evolving Trends in Family-Friendly Policies}

Family-friendly policies vary among organizations around the world. Many developed and established countries enlisted laws to help protect workers and their families. State legislators could establish statelevel family-friendly policies. Unfortunately, employers are left to create family-friendly policies that supplement the gaps in country-level and state-level policies. Additionally, country-level, state-level, and business-level family-friendly policies may not align with employee preferences and family dynamics; these topics merit a separate discussion. 


\section{Family-Friendly Policies and Challenges for Accountants}

The availability and use of family-friendly policies in the accounting industry holds some challenges of its own. The accounting industry is known for excessive work hours, required evening networking events, obligated travel, and various client obligations, which can hinder an employee's ability to manage work and family commitments (Whiting, Gammie, Herbohn, \& Cahan, 2015). The excessive work hours may result from fluctuating accounting standards, rigorous financial statement and tax deadlines, advancements in technologies, and changes to the tax laws that affect accountants' workloads (Smith, Smith, \& Brower, 2011). In turn, these various work-related stresses may restrict accountants' abilities to manage their work and family responsibilities independently. Accountants depend on their employers to establish policies that permit them to balance work and family needs, yet the accounting industry continues to experience workload challenges.

\section{Employee Turnover Intention}

Employee turnover intention is a strong indication that employees may voluntarily leave their current position, organization, or industry (Sun \& Wang, 2017). This conscious action from employees to leave may be unhealthy for specific industries with high employee turnover, like the accounting industry. Employee turnover in the accounting industry has been documented as a significant problem since 1973, creating a need to continue to assess ways to reduce turnover intentions (Hellriegel \& White, 1973; Nouri $\&$ Parker, 2020). For example, accounting firms recorded a high of $45 \%$ turnover in 1986, and yet 3 decades later, accounting industry turnover rates continue to be significantly high (Bao, Bao, \& Vasarhelyi, 1986; George \& Wallio, 2017). Houghton, Jubb, Kend, and Ng (2010) documented top executives' concerns in the accounting industry and noted their apprehension of the repercussions of high turnover rates.

\section{PURPOSE}

The purpose of this quantitative correlational study was to examine the relationship between familyfriendly policies and accountant turnover intention. The independent variables were employees' perceptions of family-friendly policies of (a) childcare support, (b) alternative work schedules, and (c) work-family culture. The dependent variable was accountant turnover intention. The targeted population consisted of accountants located in Hawaii. The implications for social change are to improve the accountants and their families' quality of life by balancing their work and family needs, allowing accountants to contribute positively to their community.

\section{RESEARCH QUESTION AND HYPOTHESES}

$\boldsymbol{R Q}$ : What is the relationship between employees' perceptions of the family-friendly policies (a) childcare support, (b) alternative work schedules, and (c) work-family culture and employee turnover intention?

H0: There is no statistically significant relationship between employees' perceptions of the family-friendly policies (a) childcare support, $(b)$ alternative work schedules, and $(c)$ work-family culture and employee turnover intention.

H1: There is a statistically significant relationship between employees' perceptions of the family-friendly policies (a) childcare support, $(b)$ alternative work schedules, and $(c)$ work-family culture and employee turnover intention.

\section{RESEARCH METHODOLOGY}

\section{Participants}

The participants consisted of accountants located in Hawaii. Eligible participants must currently or have formerly worked as an accountant within the last 3 years. Participants must have been an accountant for a 
minimum of 1 year to qualify. Participants did not have to have current family responsibilities, nor did they need to experience the use of family-friendly policies to be a participant. This strategy allowed all accountants' desires to be heard, including those that currently have families, those that may have families in the future, and those who desire working for a company that values having a family.

I recruited participants through three methods, professional organizations, academic associations, and social media. To ensure that the participants met the study's sample criteria, the survey included demographic questions that addressed the length and timing of when the individual was an accountant. The raw data included responses from 224 participants, a 13\% response rate from the 1,700 individuals contacted through the data collection procedures. The response rate is consistent with prior research that included accountants completing an online survey (Cohen et al., 2020; Jones \& Iyer, 2020).

\section{Measures}

Prior researchers used the National Study of the Changing Workforce (NSCW) survey instrument to align to their studied work and family variables. For example, Sahibzada, Hammer, Neal, and Kuang (2005) designed scales for variables such as flexible work arrangements, care for family members, and workfamily culture, while utilizing the NSCW survey instrument. O'Connor and Cech (2018) designed a scale for the employee turnover intention variable utilizing the NSCW survey instrument. I incorporated these scales within this study. See Figure 1 for the list of independent and dependent variables, the scales used to measure the variables, and the prior researchers that used the NSCW survey instrument that aligned to the variable.

\section{FIGURE 1 SURVEY INSTRUMENT ALIGNMENT}

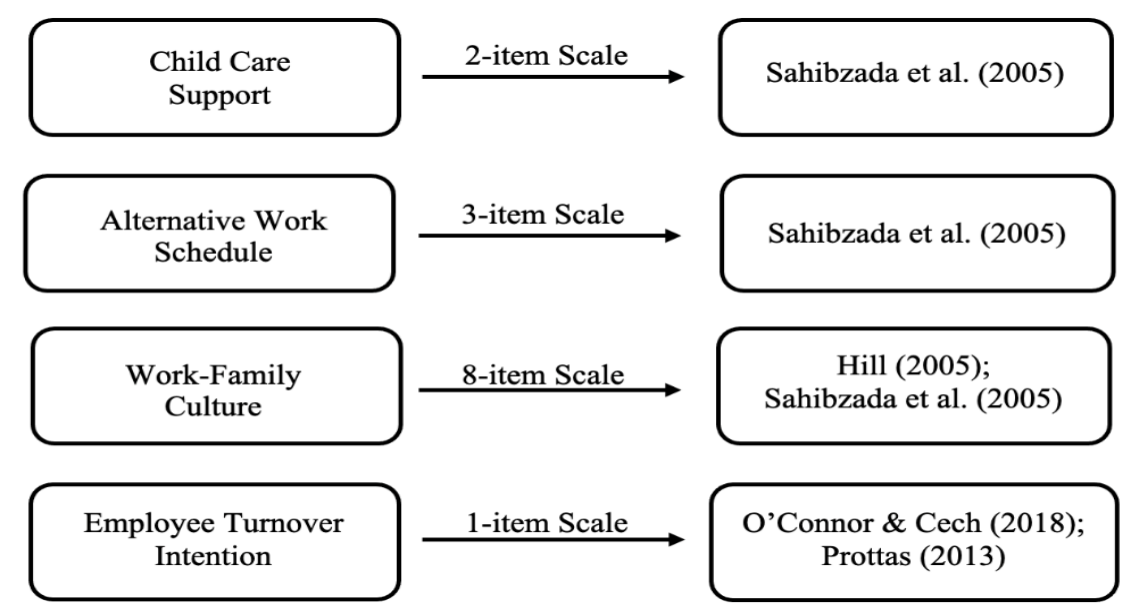

\section{PRESENTATION OF THE FINDINGS}

\section{Descriptive Statistics}

For descriptive statistics, I computed the means and standard deviations for all independent and dependent variables. I then generated frequencies on the categorical variables and split them into two categories: personal-related demographics and work-related demographics, as displayed in Appendix A. I also created a correlational matrix of all the independent variables, which is shown in Appendix B.

\section{Inferential Statistics}

To assess the hypotheses, I computed a multiple linear regression model to estimate the parameters of the relationships between the independent and dependent variables. In the model, I used a significance level of 0.05 along with a two-tailed nondirectional test. All the independent variables (childcare support, 
alternative work schedules, and work-family culture) and significant covariates were included in the model. Based on suggestions by prior researchers, I assessed a few models that included controls such as age, marital status, number of work hours, gender, ethnicity, number of children, and CPA status (Chen et al., 2018; Cohen et al., 2020; Feeney \& Stritch, 2019; Robson, Wholey, \& Barefield, 1996). Age and CPA status were the two covariates that displayed significant relationships with the dependent variable, which Chen et al. (2018) and Robson et al. (1996) also found significant. The model represented the effects that the variables had on the dependent variable (employee turnover intention). As displayed in Table 1 and Table 2, the results indicated the model could significantly predict employee turnover intention: $F(5,179)$ $=16.02 . p<0.001, R^{2}=.31$. The $R^{2}$ value indicated that approximately $31 \%$ of variation in employee turnover intention was accounted for by the linear collaboration of these independent variables.

\section{TABLE 1 MODEL SUMMARY}

\begin{tabular}{ccccc}
\hline Model & $R$ & $R^{2}$ & Adjusted $R^{2}$ & $\begin{array}{c}\text { Std. error of the } \\
\text { estimate }\end{array}$ \\
\hline 1 & $.56^{\mathrm{a}}$ & .31 & .29 & .58 \\
\hline
\end{tabular}

Note. $R=$ Correlation coefficient; $R^{2}=$ Coefficient of determination; Std. = Standard.

a. Predictors: (Constant), Childcare, Schedule, Culture, Age50+, CPA. Dependent variable: Turnover.

TABLE 2

ANOVA

\begin{tabular}{lccccc}
\hline \multicolumn{1}{c}{ Model } & Sum of squares & $d f$ & Mean square & F & Sig. \\
\hline Regression & 26.94 & 5 & 5.39 & 16.02 & $.000^{\text {b }}$ \\
Residual & 60.21 & 179 & .34 & & \\
Total & 87.15 & 184 & & & \\
\hline
\end{tabular}

Note. $d f=$ Degree of freedom; Sig. = Significance

The model presented in Table 3 displayed that all three independent variables were significant at the 0.05 level. Childcare support was significant $(t=-1.99, p=.048, \beta=-.15)$, alternative work schedule was significant $(t=-2.11, p=.036, \beta=-.15)$, and work-family culture was significant $(t=-3.68, p=.000, \beta=$ $-.27)$ within the model. Based on these results, the null hypothesis was rejected and the alternative hypothesis was accepted.

TABLE 3

MULTIPLE REGRESSION COEFFICIENTS

\begin{tabular}{lccccc}
\hline \multicolumn{5}{c}{ Unstandardized } & \multicolumn{2}{c}{ Std. coef. } & & \\
Variable & $b$ & Std. error & $\beta$ & $t$ & Sig. \\
\hline Constant) & 3.43 & 0.25 & & 13.79 & 0.000 \\
Childcare & -0.12 & 0.06 & -0.15 & -1.99 & 0.048 \\
Schedule & -0.36 & 0.17 & -0.15 & -2.11 & 0.036 \\
Culture & -0.31 & 0.08 & -0.27 & -3.68 & 0.000 \\
Age50+ & -0.28 & 0.10 & -0.18 & -2.76 & 0.006 \\
CPA & -0.31 & 0.13 & -0.15 & -2.34 & 0.021 \\
\hline
\end{tabular}

Note. $\beta=$ Beta; Std. $=$ Standard Coef. $=$ Coefficients; Sig. $=$ Significance. 
Lastly, I ran specific models to identify any differences in the significance levels of independent variables as they related to turnover intention between key demographic segments. The three segmentation schemes that I studied included participants that were parents versus not a parent, gender, and age as displayed in Table 4 and Table 5. For participants that were parents $(\mathrm{N}=82)$, childcare support and alternative work schedule were significant at the .05 level, while work-family culture was not significant $(p=.055)$. Interestingly, age remained significant, while CPA status was no longer significant $(p=.808)$ for participants that were parents. For participants that were not parents $(\mathrm{N}=95)$, work-family culture was the only significant independent variable at the .05 level, while childcare support and alternative work schedule were not significant ( $p=.953$ and $p=.472$, respectively). Further, age was no longer significant ( $p=.144)$, while CPA status maintained a level of significance for participants that were not parents.

For female participants $(\mathrm{N}=87)$, childcare support and work-family culture were significant at the .05 level, while alternative work schedule was not significant $(p=.543)$. Moreover, age is significant, while CPA status was not significant $(p=.316)$ for female participants. For male participants $(N=88)$, workfamily culture was the only significant variable at the .05 level, while childcare support and alternative work schedule were not significant ( $p=.339$ and $p=.056$, respectively). Also, age was not significant $(p=$ $.105)$, while CPA status was significant at the .05 level for male participants.

For the last demographic groups, I segmented the participants based on various age groups. For participants aged 29 and younger $(\mathrm{N}=36)$ and aged 40 to $49(\mathrm{~N}=30)$, none of the independent variables were significant at the .05 level. While childcare support and work-family culture remained significant for ages 30 to 39. Work-family culture and CPA status remained signification for ages 50 and older.

TABLE 4 SUMMARY OF BETA COEFFICIENTS FOR EACH DEMOGRAPHIC GROUP

\begin{tabular}{cccccc}
\hline & Entire sample & Parents & Not parents & Females & \multicolumn{2}{c}{ Males } \\
Variable & $\beta$ & $\beta$ & $\beta$ & $\beta$ & $\beta$ \\
\hline Childcare & $-0.15^{*}$ & $-0.34^{* * *}$ & 0.01 & $-0.27^{*}$ & -0.10 \\
Schedule & $-0.15^{*}$ & $-0.28^{* *}$ & -0.08 & -0.06 & -0.20 \\
Culture & $-0.27^{* * *}$ & -0.20 & $-0.40^{* * *}$ & $-0.26^{*}$ & $-0.26^{*}$ \\
Age 50+ & $-0.18^{* *}$ & $-0.22^{*}$ & -0.14 & $-0.24^{*}$ & -0.15 \\
CPA & $-0.15^{*}$ & 0.02 & $-0.26^{* *}$ & -0.09 & $-0.19^{*}$ \\
\hline Note. $^{* * *}=p<.001 ;{ }^{* *}=p<.01 ;^{*}=p<.05$. & & & &
\end{tabular}

TABLE 5 SUMMARY OF BETA COEFFICIENTS FOR EACH AGE GROUP

\begin{tabular}{|c|c|c|c|c|c|}
\hline & $\begin{array}{l}\text { Entire } \\
\text { sample }\end{array}$ & $\begin{array}{l}\text { Age } 29 \text { and } \\
\text { younger }\end{array}$ & $\begin{array}{c}\text { Age } \\
30-39\end{array}$ & $\begin{array}{c}\text { Age } \\
40-49\end{array}$ & Age 50 and older \\
\hline Variable & $\beta$ & $\beta$ & $\beta$ & $\beta$ & $\beta$ \\
\hline Childcare & $-0.15^{*}$ & -0.07 & $-0.32^{*}$ & -0.36 & -0.05 \\
\hline Schedule & $-0.17^{*}$ & -0.11 & -0.16 & -0.30 & 0.15 \\
\hline Culture & $-0.29^{* * *}$ & -0.34 & $-0.41^{* *}$ & 0.03 & $-0.30^{*}$ \\
\hline $\mathrm{CPA}$ & $-0.16^{*}$ & -0.12 & 0.00 & -0.00 & $-0.50^{* * *}$ \\
\hline
\end{tabular}




\section{Summary of Findings}

The results of the data analysis yielded several findings that supported the rejection of the null hypothesis as the collective relationship between (a) childcare support, (b) alternative work schedules, (c) work-family culture were significantly related to employee turnover intention. The findings indicated that having childcare support, alternative work schedules, and work-family culture were associated with lower employee turnover intention. Table 4 further summarizes the results from this study and compares the results to the demographic groups. Table 5 also lists the results from this study and compares the results to the various age groups. Both theory and empirical perspectives supported these findings of family-friendly policies significantly related to turnover intentions (Surienty, Ramayah, Lo, \& Tarmizi, 2014; Yu, 2019). All assumptions seemed to be satisfied besides possible presence of heteroscedasticity. To address potential violations of the homoscedasticity assumption, I used bootstrapping which yielded the same significant results.

\section{Theoretical Implications and Future Research}

This quantitative study explored how family-friendly policies relate to employee turnover intention. The findings for this study provided insights on how childcare support, alternative work schedule, and work-family culture relate to accountant turnover intention. The first restriction of this study was that the conclusion only reflects the relationships between the noted variables and not causation. To address this constraint, future researchers could analyze these topics through a qualitative or mixed-method study. A qualitative approach could highlight other influential family-friendly policies that were not introduced in this quantitative study or reveal the decision-making process on availability and usage of such policies. A mixed-method approach would allow the researcher to collect structured data on family-friendly policy desires and then elaborate on certain topics within semistructured interviews.

Further research could involve adding various controls or analyzing different independent variables. Prior researchers used other controls such as marital status, number of work hours, gender, ethnicity, and number of children within their studies of family and work conflicts (Chen et al., 2018; Cohen et al., 2020; Feeney \& Stritch, 2019; Robson et al., 1996). Other considered independent variables related to familyfriendly policies include work location flexibility and elderly care. Work location flexibility only started to become focused onto the accounting industry because of the COVID-19 pandemic. Moreover, past researchers did not find elderly care significantly related to turnover intention, but this may change as the demographics of the workforce change and their families age (O'Connor \& Cech, 2018). Recommendations for future research starts with utilizing other research methods and variables.

The second restriction was that the study involved turnover intention, while actual turnover may result in different findings. Actual employee turnover measurements could be used instead of turnover intention. Lastly, the study was limited to accountants located in Hawaii and included all types of accountants, ranging from an accountant, bookkeeper, auditing clerk, auditor, financial analyst, financial manager, personal financial advisor, to tax professional. Limiting the sample to a specific group may help address differences between locations and position types. Additionally, further research could address the possible permanent changes that employers made because of the COVID-19 pandemic. These recommendations could lead to further insights as to why accountant turnover was higher than ideal turnover rates and how to best retain accountants in the future.

\section{Limitations}

Limitations are circumstances that are outside of the researcher's control and could lead to a weakness of the study (Theofanidis \& Fountouki, 2018). The first limitation was the timing of the survey given the sensitivity of accountants' workloads throughout the year which could affect their ability to use the familyfriendly policies. The data were collected over a 2-week period in February to avoid bias or low response during tax season, which was extended into May of 2021 because of COVID-19. A second limitation was the use of self-reported surveys, which could cause participants to inconsistently interpret the survey questions. Despite this limitation, Bernecker et al. (2018) agreed that the use of self-reported surveys gives researchers the control over variables tested and permits participant confidentiality. A third limitation was 
that the results of the study were limited by the honesty and thoroughness of the participants' responses. To address the second and third limitations, I conducted a pilot test on the survey to ensure that the wording of the survey instructions were appropriate and to increase the reliability of the instrument (Afonja, 2019).

\section{CONCLUSION}

Accounting firms recorded a high of $45 \%$ turnover in 1986, and yet 3 decades later, the accounting industry turnover rates continue to be significantly higher than acceptable levels (Bao et al., 1986; George $\&$ Wallio, 2017). Prolonged high turnover rates have caused a shortage of accountants in 2017; unfortunately managers have unsuccessfully responded to these avoidable circumstances (George \& Wallio, 2017). Solving the high turnover is necessary to replenish the accountant shortage and protect the industry's reputation for supporting its employees.

This research could aid in the process of improving retention in the accounting industry. The theoretical framework for this study was social exchange theory. Based on this theory, three main themes emerged from this study, including (a) formal family-friendly policies significantly related to turnover intention, (b) informal work-family culture significantly related to turnover intention, and (c) subgroups displayed different relations between family-friendly policies and turnover. Formal family-friendly policies such as childcare support and alternative work schedule could give accountants authority to balance their work and family needs, especially given the extra time commitments expected by the industry. Informal familyfriendly policies grant accountants confidence that their use of such policies will not result in negative repercussions. Finally, the findings from subgroups indicate the unique support accountant's desire.

The findings from this study highlighted the need for action from workers, employers, and government agencies. Workers must express their concerns so management is aware of their work-family conflicts. Employers must implement policies and protectors to ensure the policies can and will be utilized. Government agencies at the state and federal levels can review current research and align policies to match the needs of the present workforce. Studies such as this can support the use of certain policies, but the research can only make an impact once applied. Collectively, organizations and individuals should support each other during this learning process to ensure union while making a positive change to the work environment.

\section{REFERENCES}

Afonja, A.F. (2019). Family-friendly workplace policies as predictors of sustainable workforce in the service industry in Lagos State, Nigeria. Journal of Organizational Psychology, 19(2), 11-17. doi:10.33423/jop.v19i2.2040

Afzal, S., Arshad, M., Saleem, S., \& Farooq, O. (2019). The impact of perceived supervisor support on employees' turnover intention and task performance: Mediation of self-efficacy. Journal of Management Development, 38(5), 369-382. doi:10.1108/JMD-03-2019-0076

Ahmad, A., Shaw, N.E., Bown, N.J., Gardiner, J., \& Omar, K. (2016). The impact of negative work home interface on intention to leave and the role of flexible working arrangements in Malaysia. The Journal of Developing Areas, 50(5), 507-515. doi:10.1353/jda.2016.0066

Al-Shbiel, S.O., Ahmad, M.A., Al-Shbail, A.M., Al-Mawali, H., \& Al-Shbail, M.O. (2018). The meditating role of work engagement in the relationship between organizational justice and junior accountants' turnover intentions. Academy of Accounting and Financial Studies Journal, 22(1), 1-23. Retrieved from https://www.abacademies.org/articles/the-mediating-role-of-workengagement-in-the-relationship-between-organizational-justice-and-junior-accountants-turnoverintention-6839.html

Bae, K.B., \& Yang, G. (2017). The effects of family-friendly policies on job satisfaction and organizational commitment: A panel study conducted on South Korea's public institutions. Public Personnel Management, 46(1), 25-40. doi:10.1177/0091026016689669 
Bagger, J., \& Li, A. (2014). How does supervisory family support influence employees' attitudes and behaviors? A social exchange perspective. Journal of Management, 40(4), 1123-1150. doi:10.1177/0149206311413922

Bao, B.H., Bao, D.H., \& Vasarhelyi, M.A. (1986). A stochastic model of professional accountant turnover. Accounting, Organizations \& Society, 11(3), 289-296. doi:10.1016/03613682(86)90026-7

Bernecker, S.L., Rosellini, A.J., Nock, M.K., Chiu, W.T., Gutierrez, P.M., Hwang, I., . . \& Kessler, R.C. (2018). Improving risk prediction accuracy for new soldiers in the U.S. Army by adding selfreport survey data to administrative data. BMC Psychiatry, 18(1), 1-12. doi:10.1186/s12888-018$1656-4$

Blau, P.M. (1964). Justice in social exchange. Sociological Inquiry, 34(2), 193-206. doi:10.1111/j.1475682x.1964.tb00583.x

Cannon, N.H., \& Herda, D.N. (2016). Auditors' organizational commitment, burnout, and turnover intention: A replication. Behavioral Research in Accounting, 28(2), 69-74. doi:10.2308/bria51455

Chen, W., Zhang, Y., Sanders, K., \& Xu, S. (2018). Family-friendly work practices and their outcomes in China: The mediating role of work-to-family enrichment and the moderating role of gender. International Journal of Human Resource Management, 29(7), 1307-1329. doi:10.1080/09585192.2016.1195424

Cohen, J.R., Dalton, D.W., Holder-Webb, L.L., \& McMillan, J.J. (2020). An analysis of glass ceiling perceptions in the accounting profession. Journal of Business Ethics, 164(1), 17-38. doi:10.1007/s10551-018-4054-4

de la Torre-Ruiz, J.M., Vidal-Salazar, M.D., \& Cordón-Pozo, E. (2019). Employees are satisfied with their benefits, but so what? The consequences of benefit satisfaction on employees' organizational commitment and turnover intentions. International Journal of Human Resource Management, 30(13), 2097-2120. doi:10.1080/09585192.2017.1314315

Engelbrecht, A., \& Samuel, O.M. (2019). The effect of transformational leadership on intention to quit through perceived organizational support, organizational justice and trust. South African Journal of Economic and Management Sciences, 22(1), e1-e8. doi:10.4102/sajems.v22i1.2338

Feeney, M.K., \& Stritch, J.M. (2019). Family-friendly policies, gender, and work-life balance in the public sector. Review of Public Personnel Administration, 39(3), 422-448. doi:10.1177/0734371X17733789

Garg, S., \& Agrawal, P. (2020). Family-friendly practices in the organization: A citation analysis. International Journal of Sociology and Social Policy, 40(7/8), 559-573. doi:10.1108/IJSSP-122019-0251

George, J., \& Wallio, S. (2017). Organizational justice and millennial turnover in public accounting. Employee Relations, 39(1), 112-126. doi:10.1108/ER-11-2015-0208

Geurts, S.E., Taris, T., Kompier, M.J., Dikkers, J.E., Van Hooff, M.M., \& Kinnunen, U. (2005). Workhome interaction from a work psychological perspective: Development and validation of a new questionnaire, the SWING. Work \& Stress, 19(4), 319-339. doi:10.1080/02678370500410208

Gim, G.C.W., \& Ramayah, T. (2020). Predicting turnover intention among auditors: Is WIPL a mediator? The Service Industries Journal, 40(9-10), 726-752. doi:10.1080/02642069.2019.1606214

Hellriegel, D., \& White, G.E. (1973). Turnover of professionals in public accounting: A comparative analysis. Personnel Psychology, 26(2), 239-249. doi:10.1111/j.1744-6570.1973.tb01135.x

Hill, J.E. (2005). Work-family facilitation and conflict, working fathers and mothers, work-family stressors and support. Journal of Family Issues, 26(6), 793-819. doi:10.1177/0192513x05277542

Homans, G.C. (1958). Social behavior as exchange. American Journal of Sociology, 63(6), 597-606. doi:10.1086/222355

Houghton, K., Jubb, C., Kend, M., \& Ng, J. (2010). The future of audit: Keeping capital markets efficient. Australia: Australian National University Press. doi:10.22459/FA.08.2010 
Hwang, W. (2019). The effects of family-friendly policies and workplace social support on parenting stress in employed mothers working nonstandard hours. Journal of Social Service Research, 45(5), 659-672. doi:10.1080/01488376.2018.1501790

Jones, A., III, \& Iyer, V.M. (2020). Who aspires to be a partner in a public accounting firm? A study of individual characteristics and gender differences. Accounting Horizons, 34(3), 129-151. doi:10.2308/horizons-18-168

Las Heras, M., Bosch, M.J., \& Raes, A.M.L. (2015). Sequential mediation among family friendly culture and outcomes. Journal of Business Research, 68(11), 2366-2373. doi:10.1016/j.jbusres.2015.03.042

Low, M.P., Ong, S.F., \& Tan, M.P. (2017). Would internal corporate social responsibility make a difference in professional service industry employees' turnover intention? A two-stage approach using PLS-SEM. Global Business \& Management Research, 9(1), 24-41. Retrieved from http://www.gbmrjournal.com/pdf/vol.\%209\%20no.\%201/V9N1-3.pdf

Moon, K.K. (2017). Voluntary turnover rates and organizational performance in the US federal government: The moderating role of high-commitment human resource practices. Public Management Review, 19(10), 1480-1499. doi:10.1080/14719037.2017.1287940

Nouri, H., \& Parker, R.J. (2020). Turnover in public accounting firms: A literature review. Managerial Auditing Journal, 35(2), 294-321. doi:10.1108/MAJ-03-2018-1823

O'Connor, L.T., \& Cech, E.A. (2018). Not just a mothers' problem: The consequences of perceived workplace flexibility bias for all workers. Sociological Perspectives, 61(5), 808-829. doi:10.1177/0731121418768235

Prottas, D.J. (2013). Relationships among employee perception of their manager's behavioral integrity, moral distress, and employee attitudes and well-being. Journal of Business Ethics, 113(1), 51-60. doi:10.1007/s10551-012-1280-Z

Rasheed, M., Iqbal, S., \& Mustafa, F. (2018). Work-family conflict and female employees' turnover intentions. Gender in Management: An International Journal, 33(8), 636-653. doi:10.1108/GM09-2017-0112

Robson, G.S., Wholey, D.R., \& Barefield, R.M. (1996). Institutional determinants of individual mobility: Bringing the professionals back in. Academy of Management Journal, 39(2), 397-420. doi: $10.2307 / 256785$

Sahibzada, K., Hammer, L.B., Neal, M.B., \& Kuang, D.C. (2005). The moderating effects of work-family role combinations and work-family organizational culture on the relationship between familyfriendly workplace supports and job satisfaction. Journal of Family Issues, 26(6), 820-839. doi:10.1177/0192513X05277546

Shauman, K., Howell, L.P., Paterniti, D.A., Beckett, L.A., \& Villablanca, A.C. (2018). Barriers to career flexibility in academic medicine: A qualitative analysis of reasons for the underutilization of family-friendly policies, and implications for institutional change and department chair leadership. Academic Medicine, 93(2), 246-255. doi:10.1097/ACM.0000000000001877

Smith, K.T., Smith, L.M., \& Brower, T.R. (2011). An examination of work-life balance perspectives of accountants. International Journal of Critical Accounting, 3(4), 367-383. doi:10.1504/IJCA.2011.042929

Socratous, M., Galloway, L., \& Kamenou-Aigbekaen, N. (2016). Motherhood: An impediment to workplace progression? The case of Cyprus. Equality, Diversity \& Inclusion, 35(5/6), 364-382. doi:10.1108/EDI-02-2016-0019

Su, X., Li, X., \& Curry, E. (2017). Understanding workplace flexibility in state agencies: What facilitates employee access? The American Review of Public Administration, 47(8), 977-996. doi:10.1177/0275074016642014

Sun, R., \& Wang, W. (2017). Transformational leadership, employee turnover intention, and actual voluntary turnover in public organizations. Public Management Review, 19(8), 1124-1141. doi:10.1080/14719037.2016.1257063 
Surienty, L., Ramayah, T., Lo, M-C., \& Tarmizi, A.N. (2014). Quality of work-life and turnover intention: A partial least square (PLS) approach. Social Indicators Research, 119(1), 405-420. doi:10.1007/s11205-013-0486-5

Thakur, S.J., \& Bhatnagar, J. (2017). Mediator analysis of job embeddedness. Relationship between work-life balance practices and turnover intentions. Employee Relations, 39(5), 718-731. doi:10.1108/ER-11-2016-0223

Theofanidis, D., \& Fountouki, A. (2018). Limitations and delimitations in the research process. Perioperative Nursing, 7(3), 155-163. doi:10.5281/zenodo.2552022

Tummers, L.G., \& Bronkhorst, B.A.C. (2014). The impact of leader-member exchange (LMX) on workfamily interference and work-family facilitation. Personnel Review, 43(4), 573-591. doi:10.1108/PR-05-2013-0080

U.S. Bureau of Labor Statistics. (2019). Business and Financial Occupations. Occupational Outlook Handbook. Retrieved from https://www.bls.gov/ooh/business-and-financial/home.htm

Wadsworth, L.L., \& Facer, R.L. (2016). Work-family balance and alternative work schedules: Exploring the impact of 4-day workweeks on state employees. Public Personnel Management, 45(4), 382404. doi:10.1177/0091026016678856

Whiting, R.H., Gammie, E., Herbohn, K., \& Cahan, S. (2015). Women and the prospects for partnership in professional accountancy firms. Accounting and Finance, 55(2015), 575-605. doi:10.1111/acfi.12066

Yu, H.H. (2019). Work-life balance: An exploratory analysis of family-friendly policies for reducing turnover intentions among women in U.S. federal law enforcement. International Journal of Public Administration, 42(4), 345-357. doi:10.1080/01900692.2018.1463541

\section{APPENDIX A}

TABLE A1

DESCRIPTIVE STATISTICS FOR PERSONAL-RELATED DEMOGRAPHIC VARIABLES

\begin{tabular}{|c|c|c|}
\hline Variable & $N$ & $\%$ \\
\hline \multicolumn{3}{|l|}{ Gender } \\
\hline Female & 87 & $50 \%$ \\
\hline Male & 86 & $50 \%$ \\
\hline \multicolumn{3}{|l|}{ Age } \\
\hline 22-29 years & 37 & $22 \%$ \\
\hline 30-39 years & 54 & $31 \%$ \\
\hline 40-49 years & 31 & $18 \%$ \\
\hline $50+$ years & 50 & $29 \%$ \\
\hline \multicolumn{3}{|l|}{ Parents } \\
\hline Not Parents & 95 & $54 \%$ \\
\hline Parents & 82 & $46 \%$ \\
\hline \multicolumn{3}{|l|}{ Number of Children } \\
\hline 1 & 38 & $57 \%$ \\
\hline 2 & 24 & $36 \%$ \\
\hline 3 or More & 5 & $7 \%$ \\
\hline
\end{tabular}

Note. $N=$ number of participants; $\%=$ percentage of participants that answered. 
TABLE A2

DESCRIPTIVE STATISTICS FOR WORK-RELATED DEMOGRAPHIC VARIABLES

\begin{tabular}{lcc}
\hline \multicolumn{1}{c}{ Variable } & $N$ & $\%$ \\
\hline Years Worked & & \\
1-5 Years & 61 & $33 \%$ \\
6-10 Years & 26 & $14 \%$ \\
11 and More Years & 98 & $53 \%$ \\
CPA & 152 & \\
Yes & 23 & $87 \%$ \\
No & & $13 \%$ \\
Size of Employer & 96 & $55 \%$ \\
$1-49$ & 58 & $33 \%$ \\
$50-99$ & 20 & $12 \%$ \\
$100+$ & & \\
Weekly Hours Worked & 40 & $23 \%$ \\
$1-40$ & 133 & $77 \%$ \\
$41+$ & & \\
\hline
\end{tabular}

Note. $N=$ number of participants; $\%=$ percentage of entire sample.

\section{APPENDIX B: CORRELATIONS BETWEEN INDEPENDENT VARIABLES}

\begin{tabular}{llccc}
\hline Variable & Test & Childcare & Schedule & Culture \\
\hline Childcare & $r$ & 1 & $.37^{* *}$ & $.50^{* *}$ \\
& $p($ 2-tailed $)$ & & $<.001$ & $<.001$ \\
\hline Schedule & $r$ & 1 & $.33^{* *}$ \\
& $p($ 2-tailed $)$ & & $<.001$ \\
\hline Culture & $r$ & & 1 \\
& $p($ 2-tailed $)$ & & \\
Note. $N=184 ;^{* *}=$ Correlation is significant at the 0.01 level (2-tailed). &
\end{tabular}

